\title{
Respuesta Fisiológica del Cultivo de Papa Cultivar Waych'a (Solanum tuberosum ssp. andigena) a Diferentes Densidades de Población de Nacobbus aberrans
}

\author{
David Cusicanquii ${ }^{1}$, Javier Franco ${ }^{2}$, Noel Ortuño ${ }^{3}$
}

\begin{abstract}
Resumen
El comportamiento del cultivar Waych'a (Solanum tuberosum spp. andigena) fue evaluado en microparcelas inoculadas con ocho densidades $(\mathrm{O}, 0.125,0.25,0.5,1,2,4$ y 8 indv./g suelo) de Nacobbus aberrans. Las evaluaciones se efectuaron a los 90, 118 y 146 días de la siembra, considerando las variables agrofisiológicas: altura de planta, longitud radical, peso fresco del follaje y peso de la raíz, y las variables nematológicas (número de nódulos, fluctuación poblacional, número de hembras y machos por nódulo). A la cosecha (160 días) se determinó el peso total y por tamaño de los tubérculos. Las densidades iniciales del nematodo afectaron principalmente a las variables agrofisiológicas. El rendimiento total fue negativamente afectado en peso y número, conforme se incrementaron las densidades de $N$. aberrans. En las variables nematológicas, se observaron diferencias en la nodulación y proporción de sexos. Los nódulos disecados presentaron por lo menos una hembra en cada uno de los estadios.
\end{abstract}

Palabras claves adicionales: Rendimiento, rosario de la papa, densidades de población, fisiología de la papa

Aceptado para publicación: julio 1997.

1 Tesista PROINPA. Programa de Investigación de la Papa. Convenio: IBTA-CIPCOSUDE, Casilla Postal 4285. Cochabamba, Solivia.

2 Investigador CIP-PROINPA.

3 Investigador IBTA-PROINPA 


\title{
Physiological Response of the Potato Crop Cv. Waych'a (Solanum tuberosum spp. andigena) to Different Population Densities of Nacobbus aberrans
}

\begin{abstract}
Summary
The performance of the cultivar Waych'a (Solanum tuberosum spp. andigena) was evaluated in microplots inoculated with eight densities $(\mathrm{O}, 0.125,0.25,0.5,1,2,4$, and $8 \mathrm{indv} . / \mathrm{g}$ of soil) of Nacobbus aberrans. Evaluations took place at 90, 118 and 146 days after planting, considering agrophysiological (plant height, root length, weight of fresh foliage and root weight) and nematological (number of nodules, population fluctuation, number of females and males per nodule) variables.

At harvest time (160 days) the total tuber yield was calculated according to weight and size. It was observed that in cV. Waych'a there was a greater effect of the initial nematode densities on the agrophysiological variables. The total yield was negatively affected in weight and number of tubers as $N$. aberrans densities increased. The nematological variables showed differences in the nodulation and proportion of sexes. The dissected nodules presented at least one female per nodule in the different stages of maturity.
\end{abstract}

Additional Index words: yield, false root-knot nematode, population densities, potato physiology.

La papa (Solanum tuberosum $L$ ) es el cultivo más importante de la zona andina de Bolivia. Entre los principales factores que determinan los bajos rendimientos están los nematodos. Cuando los nematodos están presentes en bajas densidades, por lo general causan daños imperceptibles en el desarrollo y rendimiento de las plantas; pero éstos son significativos cuando están presentes en densidades altas. Además, los daños que sufren las raíces disminuyen la cantidad de raíces funcionales, afectando la cantidad de agua y nutrientes que pueden absorber las plantas. La presencia de Nacobbus aberrans disminuye así la producción, mediante una paulatina reducción en el rendimiento de las plantas. Estudios recientes muestran que las 
pérdidas ocasionadas por $N$. aberrans varían entre el 11 a $61 \%$ en los cultivares Alpha, Gendarme y Waych'a.

Aún no se cuenta con información detallada sobre las pérdidas que este nematodo ocasiona al cultivar Waych'a y a otros cultivos de papa bajo diversas condiciones de campo.

\section{Materiales y Métodos}

El presente trabajo se realizó en la campaña 1993-94 en microparcelas de la Estación Experimental Toralapa del Programa de Investigación de la Papa (IBTA-PROINPA), ubicada en la provincia Tiraque a $71 \mathrm{~km}$ de la ciudad de Cochabamba, entre las coordenadas $17^{\circ} 31^{\prime}$ de latitud sur y $65^{\circ} 17^{\prime}$ de longitud oeste, y a una altitud de $3,430 \mathrm{msnm}$.

Las microparcelas fueron cilindros de cemento ( 0.30 de diámetro x $0.60 \mathrm{~m}$ de profundidad) enterrados en el campo. Se utilizó suelo esterilizado.

Las densidades iniciales (Pi) de $N$. aberrans se prepararon utilizando raíces noduladas de la maleza hospedante Spergula arvensis, que después de trozarse y determinar la concentración del nematodo por gramo de raíz, se incorporaron a las microparcelas en ocho densidades poblacionales (Tabla 1), que siguen una tendencia aproximadamente geométrica.

Tabla 1. Densidades de población de Nacobbus aberrans en microparcelas (Toralapa, 1993-94).

\begin{tabular}{ccc}
\hline $\begin{array}{c}\text { Densidades } \\
\text { poblacionales }\end{array}$ & $\begin{array}{c}\mathrm{N}^{\circ} \text { de nematodos por } \\
\text { microparcelas }\end{array}$ & $\begin{array}{c}\text { Inóculo Spergula arvensis por } \\
\text { microparcelas (g/suelo) }\end{array}$ \\
\hline 0.0 & 0.0 & 0.0 \\
0.125 & 4500 & 1.1 \\
0.25 & 9000 & 2.13 \\
0.5 & 18000 & 4.27 \\
1 & 36000 & 8.57 \\
2 & 72000 & 17.07 \\
4 & 144000 & 34.13 \\
8 & 288000 & 68.26 \\
\hline
\end{tabular}


La cuantificación de las poblaciones de $N$. aberrans se efectuó por el método del macerado de raíces (5) y de tinción de tejido vegetal (13).

En las microparcelas, se sembraron tubérculos-semillas certificados del cultivar Waych'a, el 21 octubre de 1993. Se hicieron tres evaluaciones con intervalos de 28 días: 90 días después de la siembra (primera floración), a los 118 días (segunda floración), y a 146 días (senectud del cultivo). Se midieron las siguientes variables morfológicas: altura de planta, longitud de raíz, peso fresco del follaje y peso fresco de la raíz, y las variables nematológicas: población final PF, tasa de multiplicación TM, número de nódulos, número de machos y hembras por nódulo, y las variables agronómicas: rendimiento total en número y peso de tubérculos por planta y de acuerdo a categorías por tamaño.

La producción perdida se calculó por la ecuación de Seinhorst citada por Franco y colaboradores (5). El experimento se condujo utilizando el Diseño de Bloques Completos al Azar con seis repeticiones; también se realizaron análisis de regresión y correlación lineal simple.

\section{Resultados y Discusión}

\section{Respuesta agrofísiológica}

\section{Altura de planta (AP)}

A mayor densidad inicial menor es el crecimiento de las plantas. A los noventa días (primera floración) se observa un mayor impacto de la densidad ( $b=1.8$ ). A los 118 días (segunda floración) el impacto es menor $(b=0.87)$. A los 146 días el efecto es casi nulo $(b=0.07)$. Aún cuando esta disminución fue cada vez mayor por cada incremento de las densidades de inóculo, este efecto fue influenciado por la época de evaluación (Figura 1). En la primera floración, por cada densidad de inóculo (Pi), la AP disminuyó en $1.8 \mathrm{~cm}$, asimismo, en la segunda floración por cada incremento de inóculo (Pi), ocurrió un decremento de $0.87 \mathrm{~cm}$ en la $\mathrm{AP}$, en cambio, en la senectud de la planta no se observó una variación marcada en la AP $(0.07 \mathrm{~cm})$, porque las plantas ya habían completado su crecimiento en esta fase. Estos cambios en la AP, son sustentados por correlaciones negativas $(r=-0.81 ; r=-0.71$ y $r=-$ 0.20 , respectivamente) y significativas $(p=0.01)$ entre la población inicial y la altura planta en cada fecha de evaluación. 


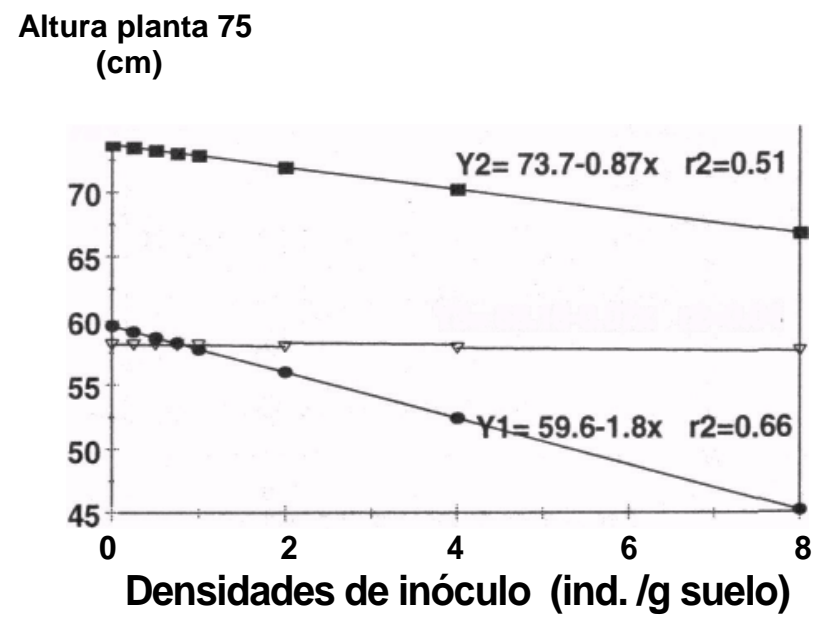

Figura 1. Efecto de las densidades de Inóculo de N. aberrans sobre la altura de planta del CV. Waych'a. Primera (Y1) y segunda floración (Y2) y senescencia del cultivo (Y3).

El efecto detrimental de la invasión de $N$. aberrans sobre la altura de la planta es más notorio a la primera floración. La disminución de altura de planta por efecto de las densidades elevadas de $N$. aberrans coincide con lo observado en otros cultivares de papa y tomate $(6,12)$.

\section{Longitud de raíz (LR)}

Se observó una disminución en el crecimiento, conforme incrementaron las densidades de inóculo ( $\mathrm{Pi}$ ) en el suelo (Figura 2). Sin embargo, este efecto varió de acuerdo a la época de evaluación. A la primera floración la LR disminuyó en $1.1 \mathrm{~cm}$ al incrementarse la densidad en una unidad en la segunda floración. En la segunda floración la LR disminuyó con $0.90 \mathrm{~cm}$ y en la senectud de las plantas la LR decreció $0.63 \mathrm{~cm}$.

La disminución de la LR se debe al daño ocasionado por la invasión y alimentación del nematodo que obstruye el sistema vascular en la raíz, ocasionando su acortamiento y la pérdida de raicillas en la porción terminal. 


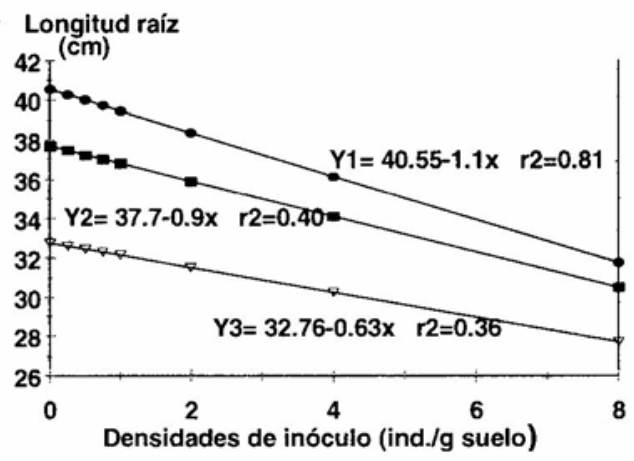

Figura 2. Efecto de las densidades de infestación de Nacobbus aberrans, sobre la longitud de la raíz del cv. Waych'a. Primera (Y1) y segunda floración (Y2) y senescencia del cultivo (Y3).

\section{Peso fresco del follaje (PFF)}

El efecto negativo de las densidades de $N$. aberrans sobre el peso fresco del follaje (PFF) fue más notorio a la primera floración. El efecto fue mínimo a la segunda floración y a la senectud (Figura 3).

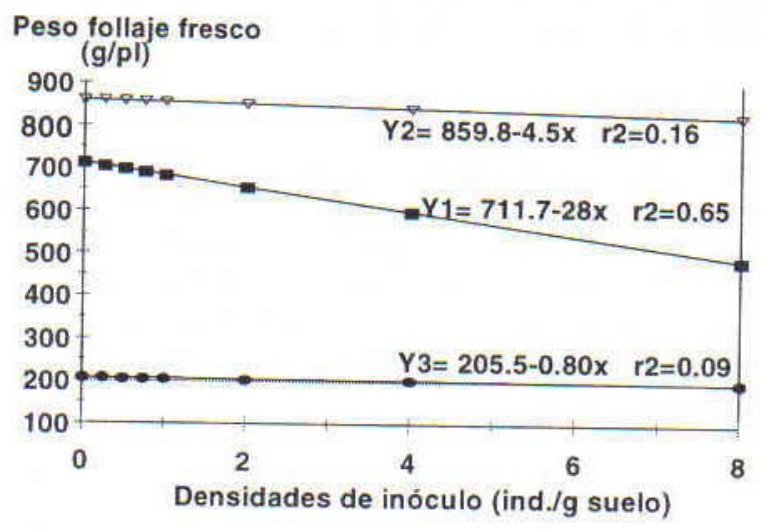

Figura 3. Efecto de las densidades de inóculo de Nacobbus aberrans sobre el peso fresco del follaje del cv. Waych'a. Primera (Y1) y segunda floración (Y2) y senescencia del cultivo (Y3). 
Las plantas atacadas desarrollan menos por la obstrucción del sistema vascular radicular porque no absorben suficiente agua y nutrientes del suelo, lo que se observa claramente a la primera floración. La diferencia entre la primera y segunda floración, principalmente en las mayores densidades, indicaría un desbalance fisiológico por el cual la planta mantiene el PFF en la segunda floración en desmedro de los procesos fisiológicos involucrados en el desarrollo y la producción de tubérculos.

El efecto de diferentes densidades sobre el PFF es menos marcado que la AP. Los nematodos al invadir las raíces ocasionan daños en los tejidos, alteran la actividad meristemática en los puntos de crecimiento, por lo que la parte aérea (vástago) disminuye, en particular en las densidades altas de inóculo, coincidiendo con lo observado por Arcos y Canto (2).

El peso seco del follaje no mostró mayor variación a diferentes densidades de inóculo, a excepción en la primera floración donde se observó ligeras tendencias descendientes.

\section{Peso fresco de la raíz (PFR)}

El peso fresco de la raíz (PFR) se incrementó conforme se incrementaron las densidades del inóculo (Pi). El mayor incremento por unidad de inoculación fue observado a la primera floración (4.39 por planta). A la segunda floración se observó un incremento similar (4.4 g); y a la senectud, el incremento fue de $6.5 \mathrm{~g}$ por planta. Si bien los daños en las densidades altas afectaron negativamente el crecimiento y la actividad de las raíces funcionales, el mayor PFR se debe a la formación de nódulos.

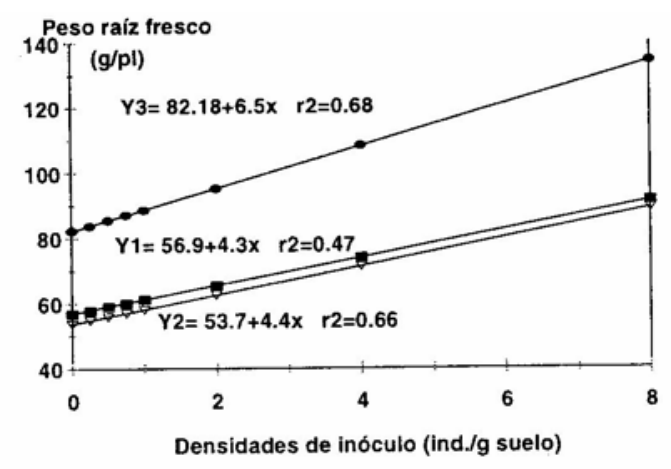

Figura 4. Efecto de los diferentes densidades de $N$. aberrans sobre el peso fresco de la raíz del cv. Waych'a Primera (Y1); segunda floración (Y2); Senescencia(Y3). 


\section{Respuesta nematológica}

\section{Población final}

La población final (Pf) se determinó con muestras radiculares de plantas extraídas de las microparcelas a los 146 días. Las Pf siguieron una tendencia paralela a las poblaciones iniciales (Pi). En la densidad más baja con $N$. aberrans se registraron 50 individuos/g raíz y en la densidad más alta 2,518.75 individuos/g raíz. Se confirmó así que la agresividad del nematodo no fue alterada por el cultivar Waych'a cuya susceptibilidad fue confirmada.

\section{Crecimiento poblacional}

Para establecer el crecimiento poblacional se utilizó la ecuación de Fujita y Utida (8) que relaciona poblaciones iniciales ( $\mathrm{Pi}$ ) con sus respectivas poblaciones finales (Pf).

Aplicando esta ecuación a los datos experimentales se observa que el nivel de equilibrio corresponde a $E=4,249$ ind/g raíz, y que el intervalo máximo de reproducción (Pf/Pi) ocurre a un Pi de 0.125 ind./g suelo $(a=776.0$ x), lo que nos indica que la reproducción del nematodo es mayor a poblaciones iniciales bajas, por la baja competencia de los lugares de penetración y mayor disponibilidad de alimentos (Figura 5). El ajuste de la ecuación de Fujita y Utida fue altamente significativa $\left(R^{2}=0.96, p=0.05\right)$.

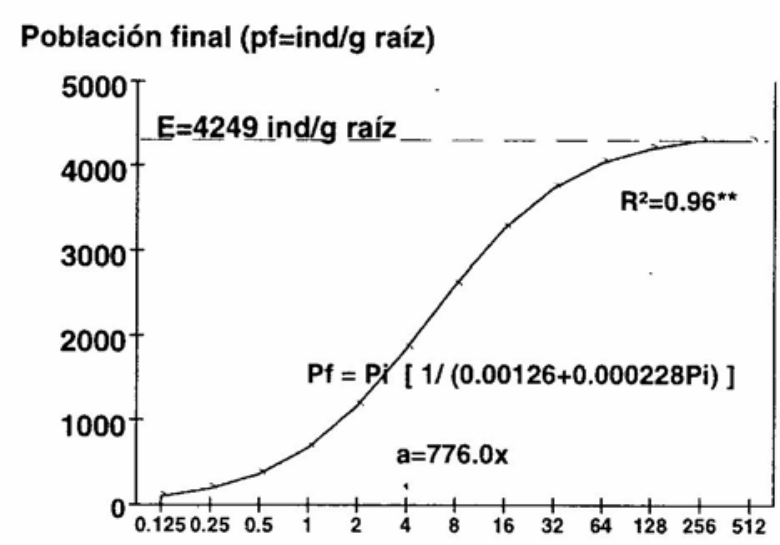

Figura 5. Curva de crecimiento de la población de N. aberrans descrita por la formula de Fujita y Utida. 


\section{Tasa de multiplicación (TM)}

La tasa de multiplicación (Pf/Pi) en función de la Pi, sigue una tendencia cuadrática (Figura 6), alcanzando su valor más alto, 624.4 para una población inicial (Pi) igual a 2, y luego va disminuyendo conforme se incrementa la población inicial. La tasa de multiplicación está relacionada con la cantidad de raíz y la capacidad reproductiva del nematodo, y a la razón macho:hembra (Figura 9) presente en el sistema radicular. Mientras el coeficiente de determinación de la tasa de multiplicación fue de 0.4 , el coeficiente obtenido mediante la ecuación de Fujita fue de 0.96. Resultados similares se han observado al estudiar diferentes $\mathrm{Pi}$ de Meloidogyne incognita raza 1 en el cultivo de girasol, TM ocurrió con la más baja población inicial, disminuyendo progresivamente al incrementar las poblaciones iniciales (11).

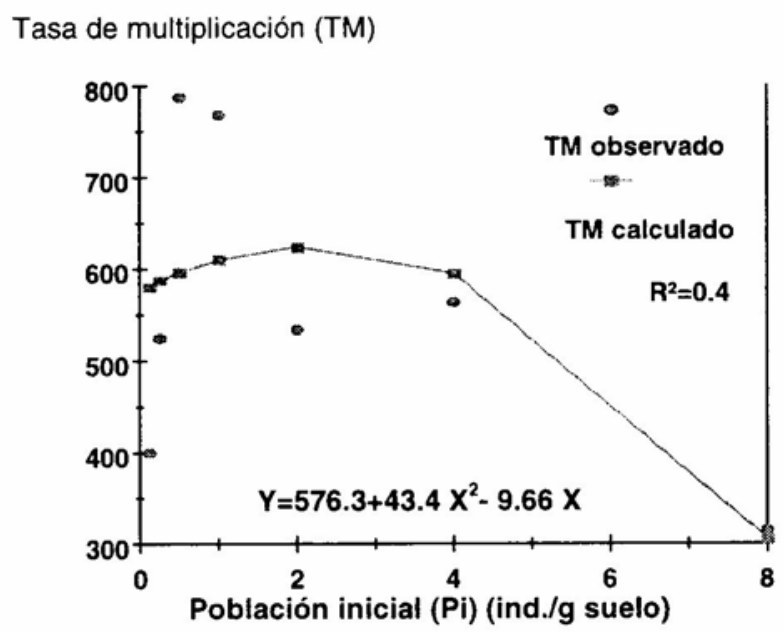

Figura 6 Tasa de multiplicación de Nacobbus aberrans de acuerdo a las densidades de inóculo descrita por la ecuación cuadrática.

\section{Número de nódulos}

El número de nódulos se incrementó en forma paralela a los 90 y 110 días a mayores densidades del inóculo de $N$. aberrans. Los nódulos aumentaron notariamente a los 146 días. El incremento en el número de nódulos es similar a los 90 y a los 118 días pero es el doble a los 146 días (Figura 7). 
El incremento de nódulos se debería a que los nódulos aumentan en número y se acorta la distancia entre los nódulos tomando la forma de rosario.

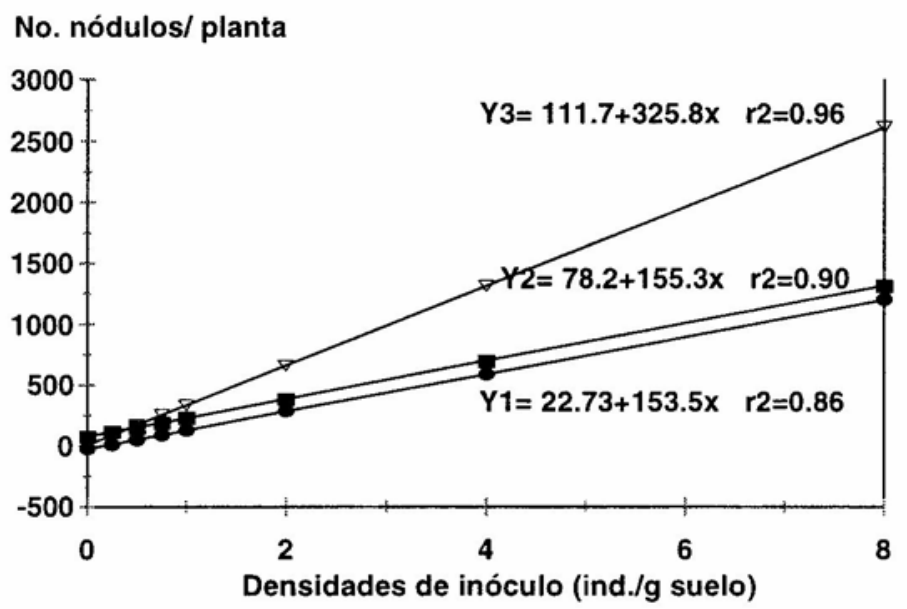

Figura 7. Efecto de densidades de inóculo de $\mathrm{N}$. aberrans sobre el número de nódulos en cv. Waych'a en tres fechas diferentes (Y1) Primera;(Y2); Segunda floración;(Y3) Senescencia

El mayor incremento en el número de nódulos a los 146 días (segunda floración) corrobora resultados anteriores que indican que el número de nódulos radicales por planta comienza a incrementarse de manera considerable cuando los tubérculos de papa empiezan a formarse (7).

\section{Número de hembras globosas, de machos y razón de sexos por nódulo}

La cantidad de hembras globosas y de machos por nódulo aumentó conforme se desarrolló el cultivo y se incrementaron las densidades de inóculo. En la disección de nódulos grandes, formados con bajas densidades de $\mathrm{Pi}$, se encontraron hasta dos hembras, en los pequeños una hembra. Con altas densidades este número varió según el tamaño del nódulo. En los nódulos grandes se observó de dos a tres hembras y una hembra en los pequeños. Las hembras halladas estaban en diferentes estados de desarrollo (Figura 8). 
En los nódulos radicales disectados también se observaron machos. Se encontraron hasta 6 machos cerca de las hembras.

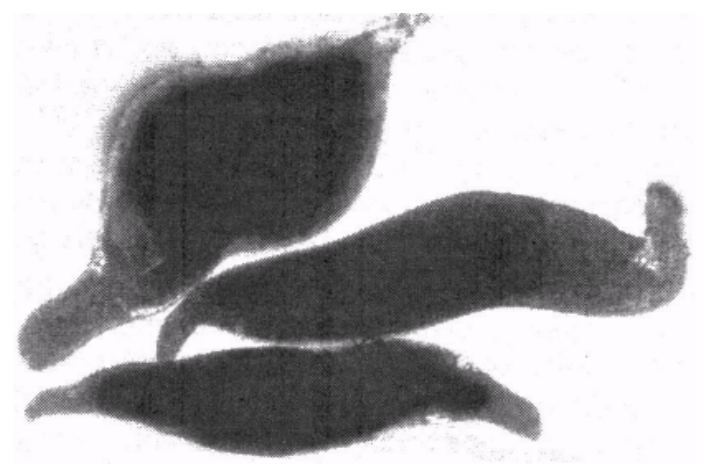

Figura 8. Hembras de Nacobbus aberrans en diferentes estados de maduración en un nódulo grande ocurrido a densidades altas de inóculo.

La razón de sexos (machos:hembras), por nódulo, mostró una relación lineal positiva con la densidad del inóculo al desarrollo de la planta (Figura 9). Esta razón en la primera floración (90 días) fue de 1.1:1 a 1.2:1, a la segunda floración (118 días) 1.28:1 a 1.8:1 y a la senescencia (146 días) de la planta se incrementó a 1.42:1 y 2.1:1. Por lo tanto, la razón macho:hembra se incrementó a medida que el hospedante alcanzó su senescencia. Este aumento de la relación de machos:hembras fue mayor en las densidades altas, lo cual responde a la competencia por alimento en el sistema radicular, que condujo a que gran proporción de nematodos jóvenes se conviertan en machos, alterando la proporción de sexos (10).

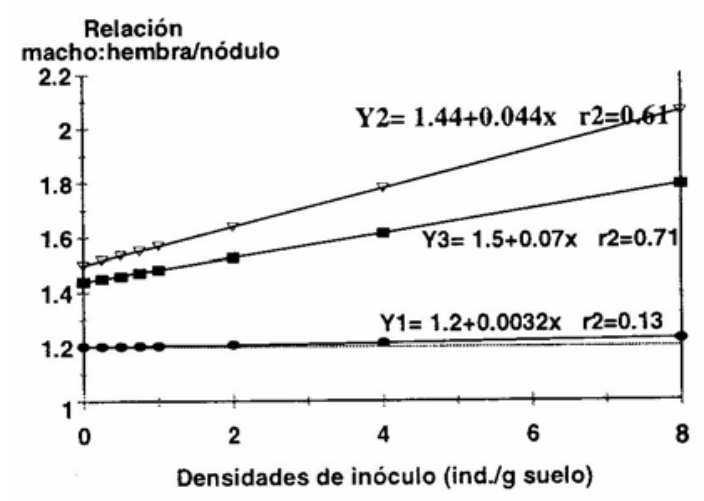

Figura 9. Relación macho: hembra por nódulo en las diferentes densidades de inóculo de N. aberrans en tres fechas (Y1) primera; (Y2) segunda floración; (Y3) senescencia. 


\section{Población de Nacobbus aberrans en la epidermis de tubérculos de diferentes categorías}

Se observaron diferencias significativas $(p=0.05)$ entre densidades poblacionales de nematodos, entre tamaños de tubérculos y para la interacción densidad por tamaño, lo que indica que estos dos factores no son independientes en la población final de $N$. aberrans en tubérculos.

El número de nematodos se incrementó en forma similar en las densidades del inóculo (Tabla 2). Al iniciarse la senectud de la planta se reduce el follaje, disminuye el volumen de las raíces potencialmente infectables, los estados infectivos invaden al tubérculo, alojándose en las lentícelas y en los dos primeros milímetros en la superficie (epidermis), sin afectar la calidad externa de los tubérculos para consumo, pero afectando su calidad en el caso de ser tubérculos-semilla.

Tabla 2. Población de $\mathrm{N}$. aberrans en la epidermis de tubérculos $\left(N^{\circ}\right.$ de nematodos por $g$ cáscara) de diferente tamaño y a ocho densidades de infestación.

\begin{tabular}{ccccc}
\hline & \multicolumn{5}{c}{ Tamaño de tubérculos } \\
\cline { 2 - 5 } Densidades & T-II & T-III & T-IV & T-V \\
\hline 0.0 & 0.00 & 0.00 & 0.00 & 0.00 \\
0.125 & 0.28 & 0.22 & 0.12 & 0.19 \\
025 & 0.36 & 0.30 & 0.15 & 053 \\
0.5 & 0.56 & 0.28 & 0.29 & 0.33 \\
1 & 0.99 & 0.98 & 0.94 & 0.58 \\
2 & 1.73 & 1.35 & 0.83 & 0.73 \\
4 & 2.35 & 1.41 & 1.40 & 0.85 \\
8 & 3.60 & 2.23 & 1.50 & 0.83 \\
\hline
\end{tabular}

$\mathrm{T}=$ Tamaño

Los resultados indican que conforme aumenta el tamaño del tubérculo aumenta el tiempo y la superficie de exposición, ofreciendo mayores oportunidades de ingreso del nematodo. 


\section{Estructura poblacional de Nacobbus aberrans en la epidermis del tubérculo}

De los tubérculos cosechados se aislaron diversos estados de desarrollo, desde el segundo estado juvenil (J-2) hasta el estado adulto (Tabla 3).

Tabla 3. Estructura poblacional de N. aberrans en la epidermis del tubérculo a ocho densidades de infestación para el cv. Waych'a a la cosecha.

\begin{tabular}{cccccccc}
\hline \multicolumn{7}{c}{ Densidades de inóculo (Pi) } \\
\hline Estados & 0.125 & 0.25 & 0.5 & 1 & 2 & 4 & 8 \\
\hline J-2 & 0.67 & 0.6 & 0.87 & 0.47 & 0.67 & 0.93 & 1.13 \\
J-3 & 1.67 & 2.0 & 2.53 & 2.40 & 3.87 & 4.2 & 7.27 \\
J-4 & 10.14 & 13.53 & 29.93 & 27.33 & 46.46 & 70.8 & 75.0 \\
H-V & 0.33 & 0.63 & 0.53 & 0.4 & 0.53 & 0.33 & 0.18 \\
M & 0.0 & 0.0 & 0.0 & 0.13 & 0.06 & 0.20 & 0.33 \\
\hline
\end{tabular}

$\mathrm{H}-\mathrm{V}=$ Hembra vermiforme

$M=$ Macho

El número de segundos estados juveniles (J-2) fue menor ai resto de los estados juveniles, pero se incrementó a medida que aumentó la densidad del inóculo. El número de individuos en el tercer estado (J-3) fue ligeramente superior al J-2, y también se incrementó a mayores densidades. El cuarto estado juvenil (J-4) encontrado en los tubérculos, fue mayor en relación a los otros juveniles (J-2 y J-3), y también se incrementó con las mayores densidades del inóculo. Se aislaron hembras vermiformes en escasa cantidad y el número de machos fue aún menor. No se encontraron machos en las concentraciones bajas, pero sí en las altas. Estos resultados indican que los estados que más se diseminan a través de tubérculos son los J2, J3 y J4.

\section{Respuesta agronómica}

\section{Pesos totales de tubérculos}

Los pesos totales de tubérculos obtenidos a la cosecha, para los diferentes densidades de inóculo, muestran una disminución en sus pesos conforme se incrementaron las densidades del inóculo (Figura 10). 
Por cada incremento de la densidad el peso total de los tubérculos por planta se redujo en $36 \mathrm{~g}$. Este efecto negativo de $N$. aberrans en el peso total de los tubérculos por planta, se debe a alteraciones fisiológicas causadas por las altas densidades del que fueron más evidentes a la primera floración, en donde se observó una mayor penetración de los J-2 y luego por la competencia alimentaria de los nematodos que ocasionan una disminución en el peso total de tubérculos conforme se incrementó la densidad (6).

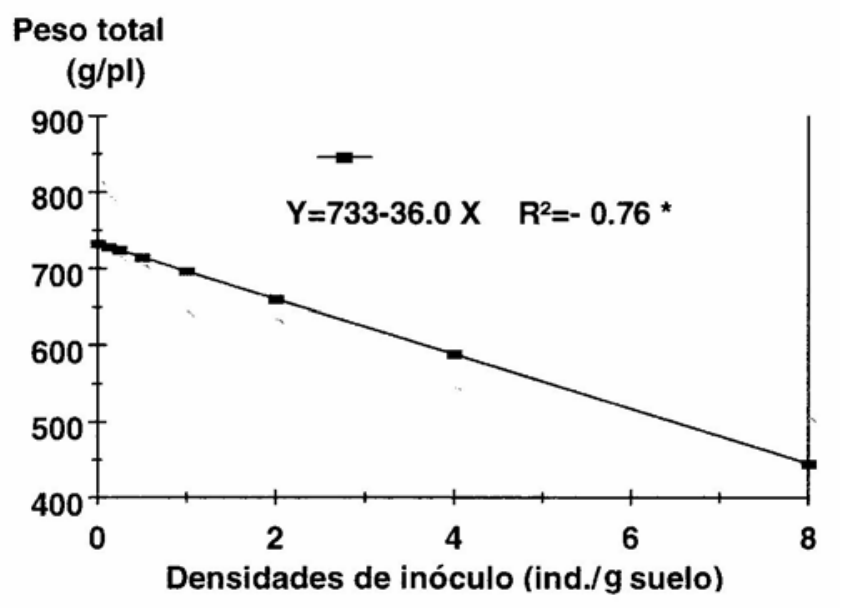

Figura 10. Efecto de densidades de inóculo de N. aberrans sobre los pesos totales de tubérculos en el cv. Waych'a.

\section{Número de tubérculos totales}

El análisis de regresión efectuado para el número de tubérculos muestra un aumento en éste como consecuencia del incremento en las concentraciones de $N$. aberrans. El número de tubérculos por planta aumentó en 0.62 por cada unidad de densidad (Figura 11). Este efecto se debería a una respuesta de compensación de la planta, que produce más tubérculos pero más pequeños. Este efecto coincide con estudios anteriores, que indican que en el peso y número de tubérculos se observaron asociaciones opuestas (9). 


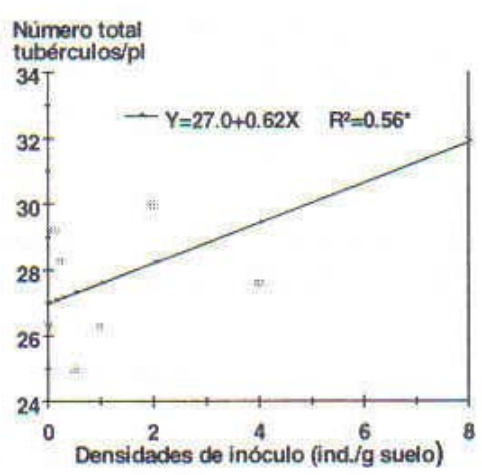

Figura 11. Efecto de densidades de inóculo de N. aberrans sobre número de tubérculos totales en el cv. Waych'a.

\section{Peso de tubérculos por tamaño}

El peso de los tubérculos de tamaño primera (Y1) y segunda (Y2) decrecieron a densidades altas de inóculo de $N$. aberrans (Figura 12). Conforme se incrementaron las densidades poblacionales del nematodo, los pesos de los tubérculos primera y segunda disminuyeron progresivamente, produciéndose más de tubérculos de tercera, cuarta y quinta (Y3, Y4, Y5). Cada incremento en la densidad del inóculo redujo el peso de los tubérculos de primera en 369 y en 299 el peso de los tubérculos de segunda.

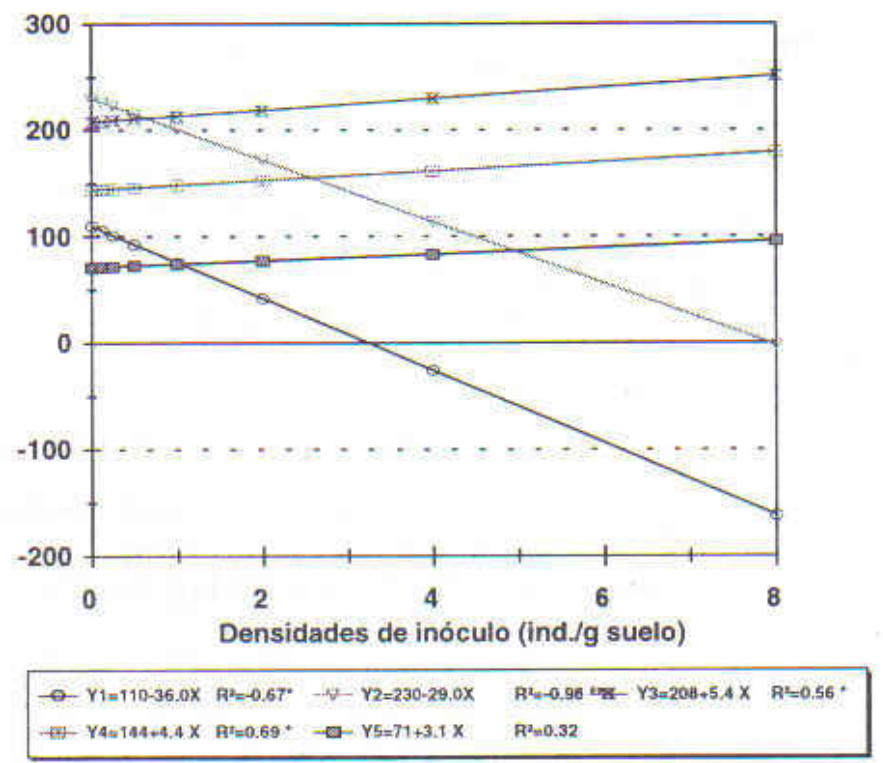

Figura 12. Efecto de densidades de infestación de N. aberrans sobre el peso de los tubérculos por tamaños en el cv. Waych'a (Y1) primera; (Y2) segunda; (Y3) tercera; (Y4) cuarta y (Y5) tamaño quinta. 
incremento en la concentración del inóculo en una unidad produjo un incremento de 5.49 en papa de tercera, $4.4 \mathrm{~g}$ en papa de cuarta y 3.19 en papa de quinta.

Las diferentes densidades afectaron la producción de papa de primera, entre el 31 y $100 \%$, que coincide con estudios preliminares realizados con el cultivar Chapara (60\%) (7).

\section{Número de tubérculos por tamaños}

El número de tubérculos primera y segunda fueron afectados negativamente por las densidades altas de inóculo. Por cada incremento de densidad de inóculo (Pi) hubo una reducción de 0.44 en el número de tubérculos primera y de 0.40 en los segunda.

Los números de tubérculos de tercera, cuarta y quinta se incrementaron. Por cada incremento en las concentraciones del inóculo (Pi) el número de tubérculos se incrementó en 0.30 en papa de tercera, 0.41 en papa de cuarta y 0.23 en papa de quinta (Figura 13).

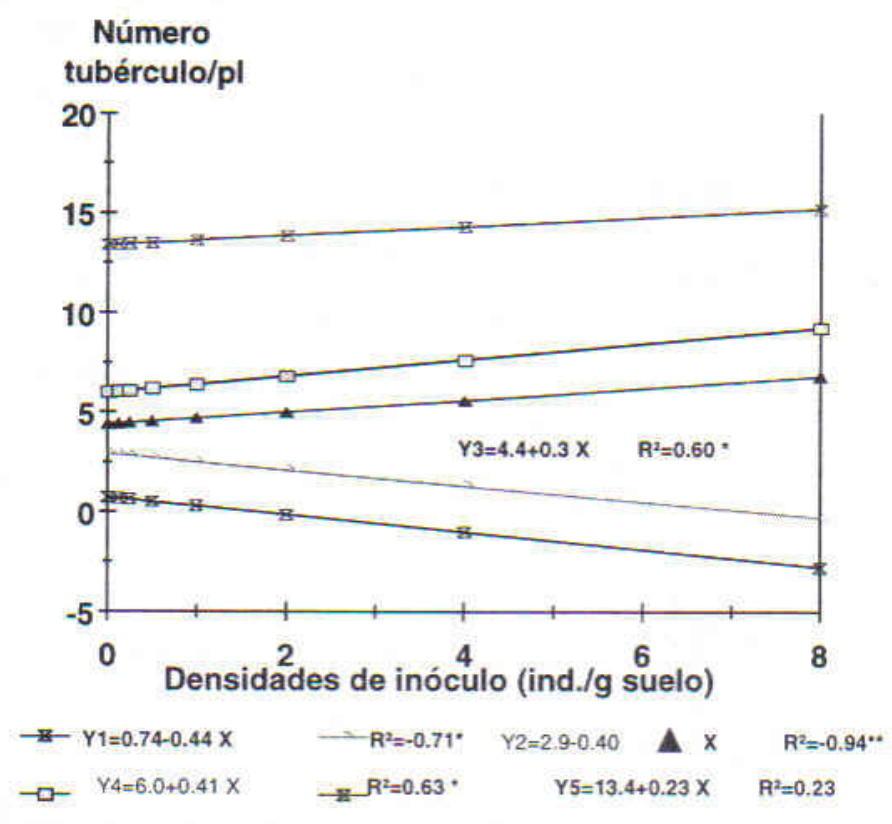

Figura 13. Efecto de densidades de infestación de Nacobbus aberrans sobre el número de tubérculos por tamaño en el cv. Waych'a (Y1) primera; (Y2) segunda; (Y3) tercera; (Y4) cuarta y (Y5) tamaño quinta. 
El análisis del rendimiento por tamaños nos dice que el número de tubérculos es inversamente proporcional al peso de los mismos. El fenómeno observado corresponde a la respuesta de la planta la que busca tener un crecimiento vegetativo mínimo y un mayor número de tubérculos de tamaño reducido, que aunque implica una menor producción de tubérculos grandes $(\mathrm{Y} 1, \mathrm{Y} 2)$, garantiza su supervivencia a través de la gran cantidad de tubérculos pequeños.

\section{Pérdidas en rendimiento ocasionadas por Nacobbus aberrara}

Analizando con la ecuación de Seinhorst (5), los efectos de diferentes densidades en el rendimiento podemos afirmar que las pérdidas mayores ocurren con las densidades más altas (32\%), mientras que las pérdidas sólo son del $1 \%$ con las densidades más bajas (Tabla 4)

Tabla 4. Poblaciones iniciales (Pi), rendimientos observados, transformados y calculados y pérdida de rendimientos para el cv. Waych'a por la ecuación de Seinhorst.

\begin{tabular}{ccccc}
\hline & \multicolumn{3}{c}{ Rendimientos kg/planta } & \\
\cline { 2 - 4 } Densidades & Observados & $\begin{array}{c}\text { Transformados } \\
\text { (unidad) }\end{array}$ & Calculados & $\begin{array}{c}\text { Pérdidas } \\
\text { (\%) }\end{array}$ \\
\hline 0.0 & 0.81 & 1 & 1 & 0 \\
0.125 & 0.79 & 0.98 & 0.989 & 1.1 \\
0.25 & 0.71 & 0.88 & 0.975 & 2.1 \\
0.5 & 0.70 & 0.87 & 0.959 & 4.1 \\
1 & 0.64 & 0.79 & 0.924 & 7.6 \\
2 & 0.61 & 0.75 & 0.863 & 13.7 \\
4 & 0.54 & 0.67 & 0.775 & 22.5 \\
8 & 0.51 & 0.62 & 0.683 & 31.7 \\
\hline
\end{tabular}

\section{Conclusiones}

Bajo las condiciones de estudio, los resultados obtenidos nos indican que las pérdidas en rendimiento están en función de la densidad de $N$. aberrans en el suelo. 
En el cultivar Waych'a los daños del nematodo son más evidentes a la primera floración (90 días). El desarrollo de la planta se ve afectado en su altura, longitud radicular y peso fresco del follaje, todo lo cual ocasiona una disminución en su capacidad productiva. Como consecuencia de ello, disminuye la producción de tubérculos tamaño primera y segunda, incrementándose los de tercera, cuarta y quinta. Sin embargo, el peso total disminuye aunque aumentó el número de tubérculos.

Altas densidades del inóculo afectan negativamente sobre la reproducción de $N$. aberrans disminuyendo su tasa de reproducción. El número de hembras y machos hallados en los nódulos dependen del tamaño del nódulo y el grado de infestación del suelo (hasta 3 hembras y 6 machos por nódulo). También se observó un incremento en la razón macho:hembra después de la segunda floración.

Los resultados indican que el grado de infección del tubérculo aumenta cuando se incrementa la densidad del inóculo y el tamaño de los tubérculos, existiendo predominancia de los estados juveniles J4 y J3, responsables de la diseminación de $N$. aberrans a través de los tubérculos.

Este trabajo fue ejecutado dentro del marco del convenio del Programa de Investigación de la Papa, PROINPA, que fue establecido entre la Secretaría Nacional de Agricultura y Ganadería de Solivia, la Cooperación Suiza al Desarrollo (COSUDE) y el Centro Internacional de la Papa (CIP).

\section{Referencias Bibliográficas}

1. Agrios, G. 1986. Fitopatología. Trad. Manuel Rodríguez. Ed. Limusa, México, p. 85-89-661-667.

2. Arcos, J.; Canto, M. 1991. Interacción entre N. aberrans y Globodera pallida. En: Resúmenes de la Reunión de la Asociación Latinoamericana de la Papa. Lima, Perú. 84 p.

3. Castillo, G.; Mendoza, M. 1984. Histopatología y desarrollo de $N$. aberrans Thorne y Allen 1944 en raíces de Capsicum annum y C. baccatum. Agrociencia. México No. 56: 85-93.

4. Franco, J.; Rincón, H. 1985. Investigaciones Nematológicas en Programas de Papa de Latinoamérica. CIP. Lima, Perú. 134 p. 
5. Franco, J.; Gonzales, A; Matos, A. 1993. Técnicas y métodos para el nematodo quiste de la papa Globodera spp. CIP-PROINPA, Cochabamba, Solivia, p. 57-67.

6. Montalvo, R. 1992. interacción Nacobbus aberrans (Thorne 1935) Thorne y Allen, 1944 y Synchytrium endobioticum (Schilberszky) Percival 1910 en dos variedades de papa. Tesis Ing. Agr. Universidad Mayor de San Simón, Facultad de Ciencias Agrícolas y Pecuarias. Cochabamba, Solivia. $124 p$.

7. Otazú, V.; Caero, G.; Hoppes, R.; Huayta, I. 1985. El rosario de la papa causado por $N$. aberrans (Thorne, 1935) Thorne y Allen 1944, su efecto en el rendimiento y algunos aspectos que inciden en su propagación y prevalencia en Bolivia. Fitopatología 20 (2) 65-70 Lima, Perú.

8. Oostenbrink, M. 1966. Major characteristics of the relation between nematodes and plants. Mededeligen Landbou, Wageningen, Netherland 66 р. 1-46.

9. Programa de Investigación de la Papa (PROINPA). Informe Anual 1990-91 IBTA/CIP/COTESU. p. 113-116.

10. Prasad, S. K.; Webster, J.M. 1967. Effect of temperature on rate of development of Nacobbus serendipiticus excised tomato roots. Nematología USA, 3: 85-90.

11. Sasanelli, N.; Di Vito, M. 1992. The effect of Meloidogyne incognita on growth of sunflower in pots. Nematología Mediterránea 20:(1) 9-12.

12. Sosa, C.; Muñoz, G. 1973. Respuesta de dos variedades de tomate (Lycopersicon esculentum) a siete niveles de población de Nacobbus serendipiticus. Nematrópica Florida, USA. 3:16-17.

13. Taylor, A. L. 1971. Introducción a la nematología vegetal aplicada. Guía de la FAO para el estudio y combate de los nematodos parásitos de las plantas. Roma, Italia. 131 p. 